\title{
VISUALISATION TECHNIQUES IN SPORT - THE MENTAL ROAD MAP FOR SUCCESS
}

\section{Radu PREDOIU ${ }^{1 *}$, Alexandra PREDOIU ${ }^{1}$, Georgeta MITRACHE ${ }^{1}$, Mădălina FIRĂNESCU ${ }^{2}$, Germina COSMA ${ }^{3}$, Gheorghe DINUŢ $\breve{A}^{4}$, Răzvan Alexandru BUCUROIU ${ }^{5}$}

\footnotetext{
${ }^{1}$ National University of Physical Education and Sport, Faculty of Physical Education and Sport, Bucharest, Romania

${ }^{2}$ Apostrof Press, Bucharest, Romania

${ }^{3}$ University of Craiova, Faculty of Physical Education and Sport, Craiova, Romania

${ }^{4}$ Technological High School of Automobile Building, Mioveni, Romania

${ }^{5}$ Focşani Tennis Club, Focşani, Romania

*Corresponding author: radu_predoiu@yahoo.com@yahoo.com
}

https://doi.org/10.35189/dpeskj.2020.59.3.4

\begin{abstract}
Athletes of the highest level in many sports (athletics, football, baseball, tennis, golf, rugby, skiing, gymnastics, swimming, basketball etc.) talk about the importance of visualising technical execution both during the training period and in competition (during warm-ups, during breaks in official games, before throws, jumps, free kicks etc.).Visualisation techniques can improve motor skills, grow muscle strength, increase selfconfidence, attention concentration and decrease anxiety. Through the use of imagery, pain management, endurance, performance motivation and physical performance can also be enhanced in athletes. To achieve the best results, visualisation techniques should include the five major senses (touch, hearing, sight, smell and taste) and should consider key aspects such as perspective, emotion, environment, task and timing. Mental rehearsal (or visualisation) is powerful because the subconscious processes the experience as a real one (by firing those neurons that are responsible for skill acquisition), makes the person calmer and more adapted to stressful situations, and can speed up the learning process in athletes and not only. One hour of mental training a day in 6-10 sequences has a special benefit that cannot be obtained by any other means. By applying both guided imagery techniques and practice, athletes design their mental road maps for success.
\end{abstract}

Keywords: visualisation, guided imagery, mental rehearsal, mental training, athletes.

\section{Introduction}

Visualisation refers to the representation of an object or phenomenon (in its absence). The use of visualisation techniques dates back thousands of years ago and has significantly progressed in recent decades (Utay \& Miller, 2006). Visualisation involves accessing an altered state of consciousness: biochemistry and brain waves modify, and the participant becomes able to speed up healing and performance (Naparstek, 2000).

Functional MRI brain studies emphasise a change in brain activity from the left to the right hemisphere during visualisation (Newmark, 2012). It is known that the upper right quadrant of the brain is better at intuitive and imaginative tasks (Roco et al., 2015), the right hemisphere being linked to creative imagination, while the left quadrants of the brain are correlated with logical thinking, planning and organization (Popescu et al., 2015). When using the creative quadrant/part of the brain, visual imagery and therefore performance are improved. 
Researchers highlight that, through the use of imagery, performance motivation, pain management, endurance, physical performance and self-confidence are enhanced in athletes (Thelwell \& Greenless, 2003; Eddy \& Mellalieu, 2003). Using mental rehearsal (for different technical and tactical actions), both body and mind are trained. Associating physical effort with mental effort is the most important step towards success, considering the athletes' road to achieve the desired performance. Top athletes have long understood that, while the human body has its natural limits, the mind has unlimited potential. And researchers emphasized that brain health (linked to neurotrophic factors and cognitive function) can be improved by practicing martial arts - taekwondo, karate, judo, and kung fu (Zou et al., 2018).

Visualisation in the field of sport has been extensively applied after the 1984 Olympics, when specialists asserted that Olympians who had used visualisation techniques reported a positive impact on their performance and biological outcomes (Newmark, 2012).

\section{Topic addressed}

Visualisation (guided imagery) occupies a central place in the mental training process. Mental training can be used in all branches of sport, various researchers showing the positive effects obtained after performing such training based on visualisation. For example, Meyers and Schleser (1980) used mental training to improve the number of points scored by a 22year-old basketball player. At the beginning, mental practice took place outside the competition area. Subsequently, the athlete performed visualisation exercises during warmups and during breaks in official games. The athlete was also taught to relax and visualise successful scenes in problematic situations.

Figure 1 shows the number of points scored by the basketball player before and after the experimental intervention, during the 28 games played.

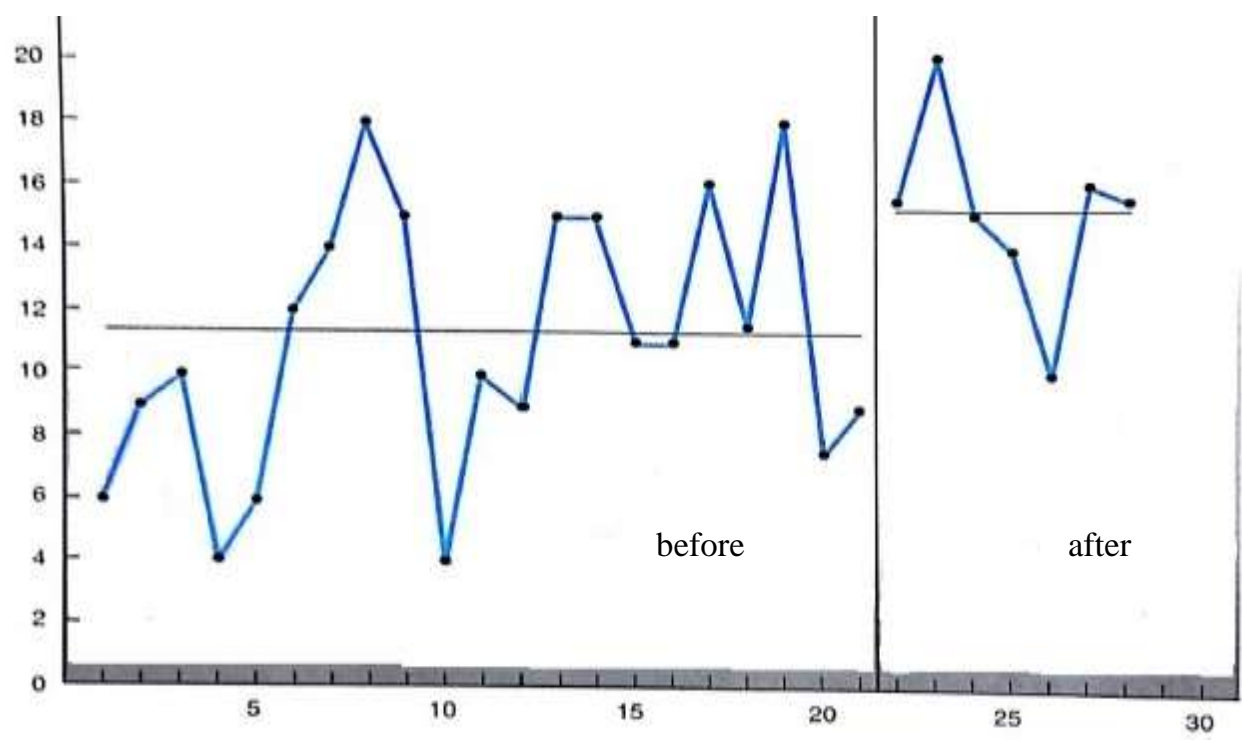

Figure 1. Number of points scored before and after mental practice (adapted after Meyers and Schlese) 
Li-Wei et al. (1992), studying table tennis players with ages between 7 and 10 years, also mention an improvement in the quality of technical and tactical performance (children learned faster and easier) following visualisation techniques combined with video analysis and relaxation.

Among the coaches' objectives regarding the athletic training process, mental practice is mandatory to be included in the training programme (in collaboration with the sports psychologist), taking into account its positive effects on both personal development and sports performance.

Some benefits of visualisation techniques are highlighted by Predoiu (2016):

- the focus of attention increases, athletes being required to reach their full potential;

- athletes learn to be more positive (mental practice is characterised by positive and successful representations - negative thoughts being eliminated);

- athletes better understand the importance of goal setting;

- self-control ability is improved, tension and fear are reduced, while self-confidence increases (Xiong, 2012);

- the athlete prepares the optimal programme of technical and tactical execution (mental practice contributes to a better organization of the temporal and spatial characteristics of the motor action);

- the athlete's thinking becomes more disciplined, organised and planned, raising awareness of the performed motor skills;

- the time needed to acquire different technical and tactical elements is reduced, and the level of preparedness for stressful situations (characteristic of competitive activity) is increased (Rogers, 2006).

Moran (1993) emphasises that mental practice should not be limited to visual aspects but can include what the person hears and feels (for example, a certain material). Maximising the efficiency of visualisation techniques can be achieved by focusing on the conditions under which guided imagery is performed. The fact that visualisation is self-learned (without requiring information from specialists) or that visualisation sessions are not systematically practised (they must have a well-established place in the training process) are limitations in acquiring visualisation efficiency. Coaches working with sports psychologists can help athletes benefit from visualisation-based mental training.

We present below a series of recommendations and topics for reflection starting from the literature data, our goal being to maximise the effects of visualisation techniques:

1. inducing a relaxation state facilitates the imagery control; the person is verbally guided to look for a comfortable position in which to remain for a while with eyes closed; a quiet place would be preferable;

Relaxation is used as a strategy to eliminate disturbing factors, the athlete's attention being directed to their own body (thoughts, emotions, inner states). Inducing the state of relaxation is very important considering that high levels of anxiety and high need for stimulation are linked with errors in various executions (Makarowski et al., 2016a; Makarowski et al., 2016b).

2. visualisation is effective, improving sports performance if mental images are full of colour, realistic, involve appropriate emotions and are controllable (LeUnes, 2008); 
Athletes must have the ability to see themselves in the position of actually performing technical and tactical actions within the competition; when motor skills are evoked, all sensory registers are used. The athlete must be able to control mental images, to turn them on or off depending on the goal pursued (in certain circumstances, other images may interfere with those of interest, distracting the athlete).

3. visualisation is a skill that can be learned;

Although some people have a better imagination/visualisation ability, almost anyone can develop this skill through exercise. It takes perseverance, some athletes mentally practising for months until they become proficient in using visualisation. Rehearsal is absolutely necessary. There are authors who consider that shorter sessions are more effective. Weinberg (1981) states that mental practice should last at least one minute but never exceed 5 minutes, while Suinn (1997), who developed the VMBR (Visuo-Motor Behaviour Rehearsal) technique in 1976, considers that the most important aspect is to avoid fatigue (regardless of the duration of mental training). We subscribe to the latter point of view - the duration of visualisation sessions may vary depending on the age and internal condition of the athlete.

4. visualisation efficiency depends not only on the athlete's imaginative ability but also on their attitude and confidence in the effectiveness of the technique - reaching the true potential can only be achieved if athletes learn to train, think and behave effectively (Harris \& Robinson, 1986);

5. some studies indicate that, as athletes gain more experience in a particular sport, the benefits of performing visualisation techniques are greater (Howe, 1991);

This can be explained by the fact that athletes with high technical and tactical skills can more easily focus on various aspects required by mental practice (compared to athletes who have reached a satisfactory level of motor skills, they control movements using more psychonervous energy).

6. in terms of age, senior athletes are generally thought to be better in using visualisation (not only because of differences in the level of motor skill development);

However, even young schoolchildren can have a good visualisation ability, taking into account that kinetic representations (rendering the image of a moving object) and transformation representations (transforming objects and their components), which ensure action planning and guidance, appear after the age of 7-8 years. Other studies show that, for example gymnasts aged between 8 and 11 years, have substantially benefited from performing visualisation techniques (Partington, as cited in LeUnes, 2008).

7. mental rehearsal is recommended to be performed in a correct time sequence, noting that visualisation in slow motion or at very high speeds (regarding motor skills) is not very useful (Bull, 2011);

With respect to the visualisation speed, we consider it useful to perform mental rehearsal in slow motion, at a normal pace and also at higher speeds (referring to movements, technical and tactical actions), depending on the aim pursued in the training process: correct understanding and learning of movement, creating the training-competition dyad or improving the speed of execution (in this situation, the athlete can relate to the objective time - the timer). In other words, mental practice for competition participation involves not only correct movements but also movements that respect the intensity and timing of the competition. Physical and mental rehearsal in slow motion brings benefits to the learning 
process, but only transient; as the speed of movement increases, the neuromuscular patterns change. Therefore, slow-motion mental practice may have no value in the context in which movement is characterised by a different speed during competition (Rushall \& Lippman, 1997).

8. many authors (Hinshaw, 1991; Whelan et al., 1991; Suinn, 1997) talk about the superiority of internal visualisation over external visualisation; in other words, mental rehearsal of motor actions/skills from an inner perspective, as if we see everything through our own eyes, is preferable;

This aspect can be explained by the fact that, through internal visualisation, a more accurate overlap of athlete's mental images with real-life situations is achieved. The "external" variant is also useful - when we observe ourselves from outside the body (for example, from the back/ side, left-up/right-up) in certain circumstances.

As mentioned above, in the early stages of learning, mental practice contributes to a better organization of movements in space and time. Therefore, moving in a certain space, observing how the upper and lower limbs are positioned in the moments before or during a technical and tactical execution (like a video analysis) and, not least, visualising the acceleration during throwing, shooting, a tennis serve etc. are also based on external representations (it is like looking at a screen and analysing all the movements for selfknowledge and development). Of course, internal visualisation should predominate in mental training sessions, with athletes imagining themselves inside their own bodies; everything that athletes see, hear, feel (emotions, inner movements, muscle tension), all the actions they perform will be closer to real life, as it is perceived in competition situations.

9. it is important for mental images to be positive; in other words, it is preferable for athletes to mentally see themselves competing well (if mental rehearsal involves negative aspects such as execution errors, the premises for sports failure are created).

Most of the Olympians practise visualisation techniques being aware of the multiple benefits provided. For example, Michael Phelps (holder of a statistical record - 23 gold medals won at the Olympic Games) declared for "The Washington Post" that he visualised a plan for each scenario (Predoiu, 2018). In 2012, his coach (Bob Bowman) explained:

He's the best I've ever seen and maybe the best ever in terms of visualization. He will see it, exactly the perfect race. And he will see it like he's sitting in the stands, and he'll see it like he's in the water. And then he will go through scenarios - what if things don't go well? [... you know if my suit ripped or my goggles break, what would I do... Phelps said]. So, he has all of this in his database, so that when he swims the race he's already programmed his nervous system to do one of those. And he'll just pick the one that happens to come up. If everything's perfect, he'll just go with the perfect one. If he has to make a change, he's got it in there. ("The Olympian's Eye: Visualization Techniques”, 2016)

But why is mental rehearsal (or visualisation) so powerful? Here is why (adapted after Poirier-Leroy, 2020): 
- visualisation makes the athlete calmer and more adapted to stressful situations;

As Michael Phelps and his coaches argued above, experiencing various scenarios in your mind helps to faster adaptation (the stressful event becomes just another session and is not perceived by the athlete as a new experience, avoiding nervousness). Therefore, mental rehearsal should be about imagining the perfect workout but also imagining the unexpected, both situations from different perspectives (views). Regarding the unexpected, the athletes' goal is to visualise themselves overcoming stressful experiences.

- when mentally rehearsing the technique, the athlete is firing those neurons that are responsible for skill acquisition.

Researchers discuss "functional equivalence" (Sollfrank et al., 2015; Lotze \& Halsband, 2006), referring to the strong overlap of neurosensory and neuromotor pathways involved during visualisation and when actually performing an action (data confirmed by both EEG and MRI investigations). Thus, mental rehearsal/mental practice can certainly speed up the learning process in the case of athletes and not only (Tunney et al., 2011; Mackay, 1981).

Through visualisation, in addition to learning facilitation, changes in thinking and the regularisation of emotional activation are achieved (we could say that what you see is what you get). Martin et al. (1999) talk about the existence of five types of visualisation that athletes use to obtain affective (anxiety and arousal regulation), cognitive (cognitive modification) and behavioural effects (strategy and skill learning and performance):

- specific cognitive issues - imagining sports skills (for example, running style, executing a football penalty);

- general cognitive issues - imagining strategies, game plan and routines ("man to man" defence, pre-finalisation phase, "hit and run" attack action etc.);

- specific motivational issues - imagining specific goals (for example, receiving a medal);

- general motivational issues (activation) - imagining emotional and somatic experiences (stress, enthusiasm, anxiety etc.);

- general motivational issues (management) - imagining situations that involve managing one's own states (to remain positive and focused after a technical/tactical error, to be confident in an important moment of the competition).

Athletes use all five types of visualisation. However, they seem to use motivational visualisation to a greater extent than cognitive visualisation (Cumming \& Hall, 2002). Other authors complement the list of types of visualisation used by athletes, such as imagining internal physiological healing processes (Driediger et al., 2006). A very important aspect is that the ability to imagine the movements of one's own body (the athlete feels the effort and tension in the muscles, has information about body balance and positioning in space) is positively associated with self-confidence and negatively correlates with the intensity of anxiety felt at the cognitive level - worry, tension (Monsma \& Overby, 2004).

- imagining the details (specific game conditions, technical and tactical actions, playing schemes and different outcomes appealing to sounds, smells, sights, muscle tension) concentration and motor skills are increasing, while trait anxiety is decreasing;

When imagining the details within the visualisation techniques, the athlete's subconscious processes the experience as a real one (thus modelling the competition during training). It is a 
fact that mental practice has positive effects on performance in a reaction time task (Shanks \& Cameron, 2000). Through visualisation, muscle strength also grows, mental training enhancing the cortical output signal; consequently, a higher level of muscle activation is recorded, and strength increases (Ranganathan et al., 2004).

One of the most widely used system goes by the acronym PETTLEP, which is from: Physical - Environment - Task - Timing - Learning - Emotion - Perspective. For example, in accordance with PETTLEP system, the athlete should wear the clothes used in competition, an environment similar to the one in which the competition will take place should be created (grass, different objects, temperature, humidity, or photographs and videos can be used), and the task should be achieved in 'real time' (with respect to the intensity and time needed to complete it). Visualisation should also be updated as the athlete's level increases. Do not forget about emotions - they should be associated with performance and incorporated into visualisation from an inner perspective. However, even if internal imagery is recommended (through the athlete's own eyes), the power of the external perspective should not be underestimated ("The Olympian's Eye: Visualization Techniques", 2016).

We present some visualisation techniques used in gymnastics and golf (adapted after Ekeocha, 2015; Newmark, 2012):

- Gymnastics: begin with progressive muscle relaxation; once the muscles are relaxed, imagine a competitive meet (use your auditory, visual and tactile senses); imagine the routines - warm up, saluting the judges before starting (as detailed as you can); imagine yourself performing the technical actions while hearing the noise in the audience (maybe the fans screaming);

- Golf: first, with the eyes closed, a state of relaxation is induced, any tension is released from the head to the feet, and breathing is controlled becoming slower and deeper; golfers imagine themselves in detail (using tactile, auditory and visual senses) playing a round of golf; they see the club, the green golf course, hear and fell the breeze through the air, fell the ground beneath their feet (the ground is calm); the athlete imagines the white golf ball following an imaginary dotted line into the hole.

It can be seen that visualisation techniques start with relaxation techniques (in a first phase, the athlete must become relaxed and calmer). We complement the existing data with some visualisation techniques used in tennis and handball (adapted after Predoiu, 2016, p. 116):

- Tennis:

Instructions (first phase): "Take a comfortable position in which you will remain for a while" $\rightarrow$ "Keep your eyelids closed" $\rightarrow$ "Pay attention to what is happening outside (what you hear, what you feel)" $\rightarrow$ "You realize that you are not interested in what is happening outside, you become bored" $\rightarrow$ "Now that you know what is happening outside, you are free to turn your attention to yourself " $\rightarrow$ "Pay attention to your moods, breathing, thoughts, emotions, inner movements".

Mental recreation of real-game conditions (second phase): "Imagine that you are on the baseline of the tennis court" $\rightarrow$ "You have the tennis racket in your hand, you look at it, you feel the tension in the muscles" $\rightarrow$ "In front of your eyes you see the net, you see the other 
side of the tennis court" $\rightarrow$ "You look at the edge of the court, you see the audience, the people watching you".

The competition-specific ambiance will be created in order to get athletes used to stressful situations so that later, in practice, a decrease or even disappearance of the negative effects of different stimuli (with anxiogenic potential) can be observed.

Before the first phase, the athlete is given the following information: "There are three verbal suggestions that you will pronounce in internal language, in parallel or shortly before the images in the mental training". Verbal suggestions and related images are (for example):

- I'm moving - imagine that you are moving as fast as you can to the other corner of the tennis court;

- I'm getting ready - imagine the correct position before hitting the ball;

- technical execution: long-line forehand, cross-court forehand, long-line backhand, crosscourt backhand etc. - imagine, feel how you accelerate the movement when the tennis racket hits the ball and visualise how the ball reaches the target set on the opponent's field.

During mental practice (after the first two phases described above), the athlete can change the place where to send the ball, can change the effect used when hitting the ball etc. every 30-45 seconds (for 5-10 minutes). Thus, in the 5-10 minutes of mental practice, the sports psychologist can intervene only once (using keywords) every 30-45 seconds in order to guide the athlete regarding the place where to send the ball. Breaks can also be included in mental training. Therefore, after every 30-45 seconds, the athlete can be verbally guided to return, for example to the middle of the tennis court, and implement previously stabilised behaviours (competitive rituals).

- Handball:

We will present some examples of verbal suggestions and related images (what the athlete must visualise) for players specialised in the position of left/right outside defender and left/right half defender, respectively, when defending in a 3:2:1 system (the attack system has one pivot). The first phase of mental training involves the existence of the same verbal commands as in the previous example (tennis), while the second phase (mental recreation of real-game conditions) involves creating the competition-specific environment, this time in a handball game. Examples of verbal suggestions and related images in handball:

- I'm defending - imagine that you tackle the attacking ball carrier to prevent shots on goal, breakthrough/ passing to the pivot and gain possession of the ball;

- Cover the inside - imagine that you perform a left-right translation movement to block/ prevent the opponent from breaking through;

- Back up (double) - imagine that you perform a step-back movement to you're your teammates next to you.

a) Left/right outside defender (wing)

Examples:

1. I cover the attacking wing, go out directly perpendicular to the opponent and cover the arm with the ball, prevent the breakthrough, return to the initial position (verbal commands like "doesn't get past me", which are negative, must be avoided);

2. I perform a left/right translational movement at 6-7 meters, close the area (inside/ outside), prevent the breakthrough, return to the initial position; 
3. in case of a blind running in, I follow the wing, hand it over to the central defender, I'm ready to cover fast passing to the pivot, I return to the initial position.

Verbal suggestions are accompanied by related images described for the athlete before the internalisation stage begins. In the 5 minutes of mental training, each of the three examples above (lasting about 20 seconds each) can be performed five times. The word "wing" triggers example 1, the word "translation" refers to example 2, and the phrase "blind running in" leads to example 3 .

b) Left/right half defender

Examples:

1. move forward and meet the opponent about 1 meter outside the free-throw line, prevent shooting or passing, return to the initial position;

2. back up (double) with the outside defender and close the area, prevent the breakthrough on the inside, return to the initial position;

3. move back and cover the inside area, prevent passing to the pivot, return to the initial position;

4. doubling with the centre defender and prevent the breakthrough or passing to the pivot, return to the initial position;

The words "move forward" trigger example 1, the phrasing "back up with the outside defender" points to example 2, the words "move back" refer to example 3, and phrasing "doubling with the centre defender" leads to example 4.

During the 6-7 minutes of actual mental training, only one intervention is made (for verbal suggestions) every 20 seconds to guide the athlete in counteracting the possible actions of the opponent.

Audio recording (verbal commands can be provided by the specialist or even by the athlete) can support the development of mental training. Finally, due to the self-educational effort, the athlete will be able to perform mental training on their own, acquiring good mental plasticity.

\section{Conclusion}

Given that the neuromotor pathways are the same when competing and when visualising the actions performed in competition, the learning process is increased in the case of athletes. Also, visualisation techniques contribute to the improvement of motor skills in the final stages of motor learning. Mental practice is transposed not only into correctly visualised movements but also into images of movements that respect the intensity and timing of the competition. It is recommended to mentally rehearse motor actions from an inner perspective, as if we could see everything through our own eyes (the superiority of internal visualisation over external visualisation is noticeable).

Through mental rehearsal, athletes become calmer and more adapted to difficult situations. Over time, imagining or anticipating stressful situations during competition causes a decrease in the relative significance of these situations and contributes to better management of negative emotions and thoughts, which reduces the athlete's ability to concentrate and fight. And we know that performance sports suppose the existence of a great number of stressful factors (present in training and in competition), whose effect can generate a reduced work 
satisfaction among athletes, behavioural disorders or an increased risk of burnout (adapted after Pastwa-Wojciechowska \& Piotrowski, 2016).

Associating physical effort with mental effort is a sine qua non condition for performance athletes aspiring to exceptional results and top positions in the rankings. One hour of mental training a day in 6-10 sequences has a special benefit that cannot be obtained by any other means.

\section{Authors' Contributions}

All authors have equally contributed to this study.

\section{References}

Bull, S. (Ed.) (2011). Psihologia sportului - Ghid pentru optimizarea performanțelor [Sport psychology - A guide to performance optimisation]. Trei.

Cumming, J., \& Hall, C. (2002). Athletes' use of imagery in the off-season. The Sport Psychologist, 16(2), 160-172. https://doi.org/10.1123/tsp.16.2.160

Driediger, M., Hall, C., \& Callow, N. (2006). Imagery use by injured athletes: A qualitative analysis. Journal of Sports Sciences, 24(3), 261-271. https://doi.org/10.1080/02640410500128221

Eddy, K. A. T., \& Mellalieu, S. D. (2003). Mental imagery in athletes with visual impairments. Adapted Physical Activity Quarterly, 20(4), 347-368. https://doi.org/10.1123/apaq.20.4.347

Ekeocha, T. C. (2015). The effects of visualization and guided imagery in sports performance. https://digital.library.txstate.edu/bitstream/handle/10877/5548/EKEOCHATHESIS-2015.pdf? sequence $=1$

Harris, D. V., \& Robinson, W. J. (1986). The effects of skill level on EMG activity during internal and external imagery. Journal of Sport and Exercise Psychology, 8(2), 105-111. https://doi.org/10.1123/jsp.8.2.105

Hinshaw, K. E. (1991). The effects of mental practice on motor skill performance: Critical evaluation and meta-analysis. Imagination, Cognition, and Personality, 11(1), 3-35. https://psycnet.apa.org/doi/10.2190/X9BA-KJ68-07AN-QMJ8

Howe, B. L. (1991). Imagery and sport performance. Sports Medicine, 11(1), 1-5. https://doi.org/10.2165/00007256-199111010-00001

LeUnes, A. (2008). Sport psychology (4 ${ }^{\text {th }}$ ed.). Psychology Press.

Li-Wei, Z., Qi-Wei, M., Orlick, T., \& Zitzelsberger, L. (1992). The effect of mental-imagery training on performance enhancement with 7-10-year-old children. The Sport Psychologist, 6(3), 230-241. https://doi.org/10.1123/tsp.6.3.230

Lotze, M., \& Halsband, U. (2006). Motor imagery. Journal of Physiology-Paris, 99(4-6), 386-395. https://doi.org/10.1016/j.jphysparis.2006.03.012

Mackay, D. G. (1981). The problem of rehearsal or mental practice. Journal of Motor Behavior, 13(4), 274-285. https://doi.org/10.1080/00222895.1981.10735253

Makarowski, R., Makarowski, P., \& Kamiński, Z. (2016a). Adrenaline instead of amphetamine - replacing psychoactive substances with parachute jumps. The Journal of General Psychology, 143(4), 281-297. http://dx.doi.org/10.1080/00221309.2016.1214101

Makarowski, R., Makarowski, P., Smolicz, T., \& Plopa, M. (2016b). Risk profiling of airline pilots: experience, temperamental traits and aggression. Journal of Air Transport Management, 57, 298-305. http://dx.doi.org/10.1016/j.jairtraman.2016.08.013 
Martin, K. A., Moritz, S. E., \& Hall, C. R. (1999). Imagery use in sport: A literature review and applied model. The Sport Psychologist, 13(3), 245-268. https://doi.org/10.1123/tsp.13.3.245

Meyers, A. W., \& Schleser, R. (1980). A cognitive behavioral intervention for improving basketball performance. Journal of Sport and Exercise Psychology, 2(1), 69-73. https://doi.org/10.1123/jsp.2.1.69

Monsma, E. V., \& Overby, L. Y. (2004). The relationship between imagery and competitive anxiety in ballet auditions. Journal of Dance Medicine and Science, 8(1), 11-18. https://www.researchgate.net/publication/233672759_The_Relationship_Between_Imager y_and_Competitive_Anxiety_in_Ballet_Auditions\#fullTextFileContent

Moran, A. (1993). Conceptual and methodological issues in the measurement of mental imagery skills in athletes. Journal of Sport Behavior, 16(3), 156-170. https://www.cabdirect.org/cabdirect/abstract/19931860370

Naparstek, B. (2000). What is guided imagery? https://www.healthjourneys.com/guided-imagery-101

Newmark, T. (2012). Cases in visualization for improved athletic performance. Psychiatric Annals, 42(10), 385-387. https://doi.org/10.3928/00485713-20121003-07

Pastwa-Wojciechowska, B., \& Piotrowski, A. (2016). Sources, Consequences and Methods of Coping with Stress in Police Officers. Journal of Alcoholism \& Drug Dependence, 4(4), 244-248. DOI: $10.4172 / 2329-6488.1000244$

Poirier-Leroy, O. (2020). Visualization for athletes: How to crush the competition and your workouts. http://www.yourworkoutbook.com/visualization-for-athletes/

Popescu, G., Predoiu, R., Stroescu, S., \& Radu, A. (2015). Cerebral dominance in elite Romanian female artistic gymnastics. Medimond International Proceedings, 441-446. WOS: 000360246100075

Predoiu, R. (2016). Psihologia sportului. Maximizarea performanței sportive [Sport psychology. Maximisation of sport performance]. Polirom.

Predoiu, R. (2018). In mintea campionilor [Inside the minds of champions]. Discobolul.

Ranganathan, V. K., Siemionow, V., Liu, J. Z., Sahgal, V., \& Yue, G. H. (2004). From mental power to muscle power - gaining strength by using the mind. Neuropsychologia, 42(7), 944-956. https://doi.org/10.1016/j.neuropsychologia.2003.11.018

Roco, M., Mitrache, G., Predoiu, R., \& Radu, A. (2015). Cerebral dominance and the superfactors of the Big Five model in junior handball players. Procedia - Social and Behavioral Sciences, 117, 226-231. https://doi.org/10.1016/j.sbspro.2014.02.205

Rogers, R. G. (2006). Mental practice and acquisition of motor skills: Examples from sports training and surgical education. Obstetrics and Gynecology Clinics of North America, 33(2), 297-304. https://doi.org/10.1016/j.ogc.2006.02.004

Rushall, B. S., \& Lippman, L. G. (1997). The role of imagery in physical performance. International Journal for Sport Psychology, 29, 57-72.

Rushall, B. S., Hall, M., Roux, L., Sasseville, J., \& Rushall, A. C. (1988). Effects of three types of thought content instructions on skiing performance. The Sport Psychologist, 2(4), 283-297. https://doi.org/10.1123/tsp.2.4.283

Shanks, D. R., \& Cameron, A. (2000). The effect of mental practice on performance in a sequential reaction time task. Journal of Motor Behavior, 32(3), 305-313. https://doi.org/10.1080/00222890009601381

Sollfrank, T., Hart, D., Goodsell, R., Foster, J., \& Tan, T. (2015). 3D visualization of movements can amplify motor cortex activation during subsequent motor imagery. Frontiers in Human Neuroscience, 9: 463. https://doi.org/10.3389/fnhum.2015.00463

Suinn, R. M. (1997). Mental practice in sport psychology: Where have we been, where do we go? Clinical Psychology: Science and Practice, 4(3), 189-207. 
https://doi.org/10.1111/j.1468-2850.1997.tb00109.x

The Olympian's eye: Visualization techniques. (2016).

https://owaves.com/olympians-eye-visualization-techniques/

Thelwell, R. C., \& Greenless, I. A. (2003). Developing competitive endurance performance using mental skills training. The Sport Psychologist, 17(3), 318-337.

https://doi.org/10.1123/tsp.17.3.318

Tunney, N. M., Arnold, C. E., \& Gimbel, L. M. (2011). Mental practice to facilitate learning when physical practice is unsafe: A pilot study. Physical \& Occupational Therapy in Geriatrics, 29(3), 243-254. https://doi.org/10.3109/02703181.2011.599481

Utay, J., \& Miller, M. (2006). Guided imagery as an effective therapeutic technique: A brief review of its history and efficacy research. Journal of Instructional Psychology, 33(1), 4043. https://scinapse.io/papers/134709492

Weinberg, R. S. (1981). The relationship between mental strategies and motor performance: A review and critique. Quest, 33(2), 195-213. https://doi.org/10.1080/00336297.1981.10483754

Whelan, J. P., Mahoney, M. J., \& Meyers, A. W. (1991). Performance enhancement in sport: A cognitive behavioral domain. Behavior Therapy, 22(3), 307-327. https://doi.org/10.1016/S0005-7894(05)80369-7

Xiong, J. (2012). The functions and methods of mental training on competitive sports. Physics Procedia, 33, 2011-2014. https://doi.org/10.1016/j.phpro.2012.05.316

Zou, L., Huang, T., Tsang, T., Pan, Z., Wang, C., Liu, Y., Sun, L., \& Wang, H. (2018). Hard martial arts for cognitive function across the lifespan: a systematic review. Archives of Budo, 14, 41-58. 